Universidade Tecnológica Federal do Paraná - UTFPR

Campus Ponta Grossa - Paraná - Brasil

ISSN: 1981-3686/ v. 08, n. 01: p. 1208-1215, 2014

D.O.I.: $10.3895 / \mathrm{S} 1981-36862014000100006$
Revista Brasileira de Tecnologia

Agroindustrial

\title{
CARACTERIZAÇÃO FÍSICO-QUÍMICA E ANÁLISE FITOQUÍMICA PRELIMINAR DO FRUTO NONI (Morinda citrofolia L.) PRODUZIDO NA CIDADE DE CUIABÁ - MT
}

\author{
PHYSICOCHEMICAL CHARACTERIZATION AND PRELIMINARY \\ PHYTOCHEMICAL ANALYSIS OF THE NONI FRUIT (Morinda citrofolia L.) \\ PRODUCED IN CUIABÁ CITY - MT
}

\author{
Wanessa Costa Silva Faria ${ }^{1}$; Simone Curvo Bett ${ }^{1}$; Carolina Garcia Balbino dos Santos ${ }^{1}$; Alexandre Silva \\ Brasil $^{1}$; Rubén Francisco Gauto ${ }^{1}$; Angela Marcia Selhorst e Silva Beserra ${ }^{2}$; Adriana Paiva de Oliveira ${ }^{1}$ \\ ${ }^{1}$ Programa de Pós-Graduação em Ciência e Tecnologia de Alimentos - Instituto Federal de Educação, \\ Ciência e Tecnologia de Mato Grosso - Campus Cuiabá - Bela Vista - IFMT - Cuiabá - Brasil \\ adriana.oliveira@blv.ifmt.edu.br \\ ${ }^{2}$ Faculdade de Farmácia - Universidade de Cuiabá - UNIC - Cuiabá - Brasil
}

\begin{abstract}
Resumo
Este trabalho teve como objetivo caracterizar fisico-quimicamente a polpa sem sementes e analisar o perfil fitoquímico qualitativo preliminar da polpa e dos extratos do fruto noni, Morinda citrofolia L., produzidos na cidade de Cuiabá MT. Os frutos de Morinda citrifolia Linn foram adquiridos em um produtor do perímetro urbano do município. Para as análises fitoquímicas foram utilizados os frutos in natura e, para as determinações físico-químicas foram adquiridas polpas refrigeradas e embaladas em recipiente de polietileno comercializadas na cidade. A análise fitoquímica revelou a presença de diferentes metabólitos secundários sugerindo a importância de outros estudos acerca destas substâncias e suas funções farmacológicas elou funcionais. Em relação aos parâmetros físico-químicos, os resultados indicaram que a polpa sem sementes possui $90 \%$ de água e a matéria seca é constituída principalmente por carboidratos totais e proteínas e que a quantidade de lipídios é muito pequena. Também foi observada uma elevada concentração de potássio, o que sugere que este fruto pode ser considerado uma fonte deste mineral, porém deve ser utilizado com cautela por pacientes portadores de doenças renais.
\end{abstract}

Palavras-chave: análise fitoquímica, análise físico-química, noni.

\section{Introdução}

Morinda citrofolia Linn, conhecida como "noni”, é uma árvore pequena originária da Ásia e Polinésia. Na Polinésia este é tradicionalmente utilizada como antiviral, antifúngico, antibacteriana, antitumoral, analgésico, anti-hipertensivo e antiinflamatório (KAMIYA, 2008).

Produtos fitoterápicos e naturais têm sido usados durante séculos em todo o mundo e a Morinda citrofolia Linn tem despertado interesse científico devido aos benefícios relacionados ao seu consumo. Nos trópicos é cultivada para consumo das raízes, folhas e frutos e há relatos que as raízes dessas plantas são boas fontes de antraquinonas, que estão presentes como agliconas e em menor quantidade sob a forma de glicósidos (ZIN, 2001). 
Já foram identificados aproximadamente 160 compostos fitoquímicos da planta noni, sendo a maioria compostos fenólicos, ácidos orgânicos e alcalóides (HEINICKE, 1985). No entanto, a composição varia de acordo com parte da planta que está sendo analisada. Porém, uma composição fitoquimica completa do fruto noni ainda não foi descrita, na literatura há apenas uma caracterização fitoquímica parcial do suco produzido com o fruto (MULLER, 2007).

Todas as partes da planta do noni são aproveitadas, sendo que cada uma delas possui propriedades medicinais diferentes. A parte mais consumida é o fruto, rico em vitaminas, proteínas e minerais, sob a forma de suco. Atualmente é amplamente consumido devido às várias propriedades antibactericida, analgésica, anticongestiva, antioxidante, expectorante, antiinflamatória, adstringente, laxativa, analgésica, hipotensora, purificadora do sangue, imunoestimulante e anticancerígena (COSTA, 2001). Estudos científicos têm confirmado algumas das atividades biológicas do noni descritas pelos povos polinésios como atividade antioxidante, antiinflamatória, analgésica, antibacteriana, antitumoral, entre outros (BARROS, et. al., 2008).

Atualmente, o Brasil é o quinto maior mercado de produtos à base de noni e existem cadastrados, mais de 18.000 distribuidores que comercializam o suco de Noni, cápsulas de extrato seco e do pó da planta e todos esses produtos estão à venda nas farmácias de manipulação (ASSOCIAÇÃO BRASILEIRA DE EMPRESAS DE VENDAS DIRETAS, 2006).

De acordo com estudos, o noni é constituído por $90 \%$ de água, sendo que os principais componentes da matéria seca são sólidos solúveis, fibras, proteínas e hidratos de carbono. No Brasil o consumo do noni como alimento ou como medicamento tem aumentado significativamente nos últimos anos (COSTA, 2011), a sua venda tem sido feita através de venda direta ou pelas farmácias de manipulação. Em 2007 a Agência Nacional de Vigilância Sanitária (ANVISA) divulgou um informe técnico, no qual adverte para que produtos que contiver noni não devem ser comercializados no Brasil como alimento, até que seja comprovada a sua segurança de uso (MULLER, 2007).

Diante da relevância que tem alcançado os estudos sobre as propriedades medicinais da Morinda citrofolia Linn, é fundamental que sejam feitas pesquisas que avaliem os reais benefícios que esta planta pode trazer à saúde dos consumidores. Com isso em vista, este trabalho teve como objetivo a caracterização físico-química da polpa sem semente do fruto noni e análise qualitativa fitoquímica preliminar da polpa e de extratos do fruto produzidos na cidade de Cuiabá, Estado de Mato Grosso, Brasil.

\section{Material e métodos}

Os frutos de Morinda citrifolia Linn foram adquiridos de um produtor do perímetro urbano do município de Cuiabá, MT. A exsicata de Morinda citrifolia Linn foi preparada a partir do fruto, 
folhas e flores, a mesma foi identificada através da comparação com outra exsicata previamente depositada no Herbário Central da Universidade Federal de Mato Grosso (UFMT) e posteriormente depositada no mesmo Herbário.

Para as análises fitoquímicas foram utilizados os frutos in natura enquanto que para as determinações físico-químicas foram adquiridas polpas refrigeradas e embaladas em recipientes de polietileno comercializadas na cidade.

Para análise fitoquímica qualitativa foram utilizados dois extratos e a polpa do fruto fresco. Os extratos de Morinda citrifolia Linn foram obtidos por maceração a frio em solvente hidroalcoólico a $50 \%$ (v/v), filtrado e concentrado sob pressão reduzida em rota - evaporador, sendo o solvente residual eliminado em estufa a $45^{\circ} \mathrm{C}$. Os frutos, constituídos de casca, polpa e caroços foram picados e colocados em contato com o solvente. O primeiro extrato foi preparado a partir do fruto verde e macerado por 17 dias, e o segundo extrato foi feito a partir do fruto maduro e macerado por um período de 9 dias.

Para o preparo da polpa do fruto fresco foram utilizados 35 frutos de cinco diferentes árvores e os frutos amadurecidos foram passados em peneira de aço inox com aro de madeira para separação dos caroços, no qual a polpa do fruto juntamente com a casca constituiu a amostra do fruto fresco.

A triagem fitoquímica foi feita segundo MATOS (1997) e foram avaliadas a presença de polifenóis, taninos, flavonoides, antraquinonas, saponinas, cumarinas e alcalóides.

Os parâmetros físico-químicos determinados foram umidade, carboidratos totais, carboidratos redutores, sólidos solúveis, proteínas, lipídeos, fibras dietéticas, cinzas, Na, K, pH, acidez titulável total e acidez titulável em ácido cítrico. Todas as determinações foram feitas em triplicatas. A determinação do teor de umidade foi feita por secagem direta em estufa a $105{ }^{\circ} \mathrm{C}$. Os carboidratos totais e redutores foram quantificados pelo método de Lane-Eynon. O teor de proteínas foi determinado pelo método de Kjeldahl modificado. A quantificação de lipídeos foi feita por extração direta em Soxhlet e as fibras dietéticas pelo método gravimétrico. A quantidade de cinzas foi determinada por incineração em forno mufla a $550{ }^{\circ} \mathrm{C}$. Os minerais $\mathrm{Na}$ e $\mathrm{K}$ foram quantificados por fotometria de chama e as amostras foram preparadas por decomposição por via seca e posterior diluição em meio ácido. $\mathrm{O}$ pH foi determinado pelo método potenciométrico direto e a acidez total e em ácido cítrico por titulação potenciométrica (IAL, 2005).

\section{Resultados e discussão}

A exsicata identificada e ratificada pelo Herbário Central da UFMT foi depositada no mesmo Herbário e arquivada através do número 39.689. 
A Tabela 1 mostra que a polpa do fruto fresco e o extrato do fruto verde indicaram a presença de taninos, flavonóides, antraquinonas conjugadas, saponinas, cumarinas e alcalóides. O extrato do fruto maduro mostrou um perfil fitoquímico semelhante com exceção à ausência de saponinas.

Tabela 1 - Resultados da caracterização fitoquímica qualitativa preliminar da polpa e dos extratos do fruto noni (Morinda citrifolia) coletado na cidade de Cuiabá, MT (P: resultado positivo; N: resultado negativo).

\begin{tabular}{cccc}
\hline Testes Fitoquímicos & Polpa do fruto fresco & Extrato fruto verde & Extrato fruto maduro \\
\hline Polifenóis & $\mathrm{P}$ & $\mathrm{P}$ & $\mathrm{P}$ \\
Taninos & $\mathrm{P}$ & $\mathrm{P}$ & $\mathrm{P}$ \\
Flavonóides & $\mathrm{P}$ & $\mathrm{P}$ & $\mathrm{P}$ \\
Antraquinonas & $\mathrm{P}$ & $\mathrm{P}$ & $\mathrm{P}$ \\
Conjugadas & $\mathrm{P}$ & $\mathrm{P}$ & $\mathrm{N}$ \\
Saponinas & $\mathrm{P}$ & $\mathrm{P}$ & $\mathrm{P}$ \\
Cumarinas & $\mathrm{P}$ & $\mathrm{P}$ & $\mathrm{P}$ \\
Alcalóides & $\mathrm{P}$ &
\end{tabular}

A caracterização fitoquímica completa do fruto no noni ainda não foi totalmente elucidada, no entanto estudiosos indicam os compostos fenólicos como maior grupo de micronutrientes funcionais encontrados em diversas partes da planta e no fruto (SAMPAIO, 2010). Dos grupos fenólicos presentes, a sua grande maioria encontra-se na forma das antraquinonas (DENG, et. al., 2009), porém apenas traços destes são encontrados no fruto (LIN, et. al., 2009). Entretanto, neste trabalho foram encontradas antraquinonas conjugadas em todos os extratos preparados bem como, na fruta fresca. No trabalho descrito por REYES, et. al. (2010) foi detectada no extrato etanólico e aquoso do fruto a presença de quinonas livres e esteróides, e ausência de taninos, flavonoides, alcaloides e saponinas pelo teste da espuma. No entanto, outras pesquisas afirmam a presença de alcaloides, antraquinonas, flavonoides e cumarinas corroborando com os resultados apresentados no presente trabalho (HEINICKE, 1998; PALACIOS, 2004). Estudos utilizando métodos mais sofisticados de análise já têm caracterizado quimicamente várias substâncias pertencentes a estas classes supracitadas.

Os valores das análises centesimais e físico-químicas da polpa de noni são equivalentes aos valores médios de três repetições analíticas, cujos resultados estão apresentados na Tabela 2.

O teor de umidade encontrado na polpa de noni, 90,66\%, mostra que a água é o componente mais abundante na fruta estudada e está muito próximo dos valores encontrados por CORREIA et al (2011) em noni cultivado na cidade de Horizonte, Ceará - Brasil, de CANUTO et al (2010) com noni colhido na região Centro Sul do Estado de Roraima e CHUNHIENG (2003) com frutos do Camboja.

Os carboidratos são o segundo macronutriente de maior concentração na polpa de noni, com 5,27\%. Este valor está em concordância com os valores encontrados por BARROS et al (2008), que estudaram o fruto noni cultivado na cidade de Trairi, Ceará - Brasil e o de CORREIA et 
al (2011). O valor de açúcares redutores, 3,71\%, foi próximo ao valor encontrado no trabalho descrito por CORREIA et al (2011).

Tabela 2 - Resultados obtidos na caracterização físico-química da polpa sem sementes do fruto noni (Morinda citrifolia) coletado na cidade de Cuiabá, MT.

\begin{tabular}{cc}
\hline Parâmetros Físico-Químicos & Valores* $^{*}$ \\
\hline Umidade (\%) & $90,66 \pm 0,01$ \\
Carboidratos Totais (\%) & $5,27 \pm 0,41$ \\
Carboidratos Redutores (\%) & $3,71 \pm 0,17$ \\
Sólidos Solúveis ( ${ }^{\circ}$ Brix) & $9,2 \pm 0,00$ \\
Proteínas (\%) & $2,36^{(1)}$ \\
Lipídeos (\%) & $0,04 \pm 0,01$ \\
Fibras Dietéticas (\%) & $1,00 \pm 0,05$ \\
Cinzas & $0,66 \pm 0,04$ \\
Na (mg/100g) & $19,76 \pm 0,06$ \\
K (mg/100g) & $5013 \pm 0,17$ \\
pH & $3,54 \pm 0,19$ \\
Acidez Total Titulável (g/100g) & $6,82 \pm 0,05$ \\
Acidez Titulável em Ácido Cítrico (g/100g) & $0,44 \pm 0,003$ \\
\hline Valores médios das triplicatas e desvio padrão. ${ }^{(1)}$ Proteínas $=100-($ umidade + lipídeos + cinzas + \\
carboidratos totais+fibras dietéticas)
\end{tabular}

Os teores de sólidos solúveis totais são utilizados como uma determinação aproximada de teores de açúcares, conforme MANICA et al (1998), não representando o teor exato de açúcares porque outras substâncias também se encontram dissolvidas (CHITARRA, 2005). Dentre essas substâncias dissolvidas estão os ácidos orgânicos, vitamina C, polifenóis e pectina (CORREIA et al, 2011). Neste estudo, o valor de sólidos solúveis totais foi de $9,2^{\circ}$ Brix, que foi igual ao valor encontrado por CORREIA et al (2011) e próximo do valor encontrado por BARROS et al (2008) que foi de $8,40^{\circ}$ Brix e de CANUTO (2010) que foi de $9,0^{\circ}$ Brix.

O teor de proteína foi obtido por meio da diferença entre o peso total (100\%) e o somatório dos pesos centesimais dos outros macronutrientes da fruta. O valor encontrado, em torno de 2,36\%, difere dos resultados de WEST et al (2011) com noni cultivado na Polinésia Francesa e de SHOVIC et al (2001) em noni coletado na ilha de Pohnpei situado nos Estados Federados da Micronésia, ambos foram 0,4\%. Porém, assemelha-se com o valor encontrado por CHUNHIENG (2003) e CARVALHO et al (2011) que estudaram frutas cultivadas no município de Zé Doca, Maranhão, Brasil, e no Camboja cujos resultados foram 2,5\%.

Os lipídeos apresentaram teor de $0,045 \%$, sendo o macronutriente encontrado em menor quantidade no noni, entretanto este valor se encontra dentro da faixa de concentração que varia entre 0,016 a $0,30 \%$ de acordo com resultados divulgados por outros estudos (CORREIA et al, 2011).

Com relação às fibras dietéticas, o valor obtido foi de $1,00 \%$, cujo resultado foi aproximadamente quatro vezes menor que o encontrado por SHOVIC et al (2001). CECHI (2003) afirma que frutas possuem conteúdo de fibra entre $0,1 \%$ e 6,8\%. Entretanto, a Portaria $n^{\circ} 27$, de 13 de janeiro de 1998, que se remete ao Regulamento Técnico Referente à Informação Nutricional 
Complementar, diz que o alimento pode ser considerado fonte de fibra alimentar quando apresenta, no produto acabado, 3g/100g (base integral) para alimentos sólidos e 1,5g/100mL (base integral) para líquidos, ou seja, a polpa de noni estudada não se constitui fonte de fibras dietéticas.

O conteúdo de cinzas $(0,66 \%)$ está de acordo com o encontrado por CORREIA et al (2011), WEST et al (2011) e CARVALHO et al (2011).

A polpa de noni apresentou a concentração de $\mathrm{Na}$ de $19,75 \mathrm{mg} / 100 \mathrm{~g}$, e este resultado se assemelha aos encontrados nos trabalhos de SHOVIC et al (2001) e da EUROPEAN COMMISSION (2002) que foram $21 \mathrm{mg} / 100 \mathrm{~g}$ e de 15 a $40 \mathrm{mg} / 100 \mathrm{~g}$, respectivamente.

A concentração de K foi superior a de Na, em torno de 5013 mg/100 g. Esta concentração é muito superior aos valores encontrados nos trabalhos de CHUNHIENG (2003) (3900 mg/100g), WEST et al (2011) (214,34 mg/100g), SHOVIC et al (2001) (21 mg/100g) e EUROPEAN COMMISSION (2002) (30 a 150 mg/100g) e pode ser atribuída a características do solo de cultivo. O K é um macronutriente essencial com ingestão diária recomendável de 1.875 a $5.625 \mathrm{mg} / \mathrm{dia}$, principal cátion do líquido intracelular, atuando na regulação do $\mathrm{pH}$, na osmolaridade e na transferência pela membrana celular. $\mathrm{O}$ excesso deste macronutriente pode agravar pacientes com insuficiência renal (KRAUSE \& MAHAN, 1991). Diante do resultado encontrado, o noni pode ser considerado boa fonte de potássio, porém a ingestão deve ser moderada devido ao alto teor do cátion, em torno de $100 \mathrm{~g}$ por dia.

Segundo CECHI (2003), a acidez titulável de frutas pode variar de 0,2 a 0,3\% em frutas de baixa acidez, em torno de $2 \%$ em frutas de acidez média e acima de $6 \%$ em frutas de acidez alta. A polpa de noni apresentou índice de acidez total titulável no valor de 6,82g/100g, o que o torna uma fruta de alta acidez. Este valor é maior que o encontrado por CANUTO et al (2010) e CORREIA et al (2011), respectivamente 3,2g/100g e 0,63 g/100g. O valor do índice de acidez titulável em ácido cítrico encontrado foi de $0,43 \mathrm{~g} / 100 \mathrm{~g}$. BARROS et al (2008) encontraram o valor de 0,62 g/100g em relação a este parâmetro.

\section{Conclusão}

A análise fitoquímica preliminar das amostras do fruto noni cultivados no município de Cuiabá - MT detectou a presença de diferentes classes fitoquímicas, como, taninos, flavonóides, antraquinonas conjugadas, saponinas, cumarinas e alcalóides sugerindo a importância de maiores estudos acerca destas substâncias e suas funções farmacológicas ou funcionais. A caracterização físico-química revelou que a polpa do fruto possui alto teor de umidade e que a matéria seca é constituída principalmente por carboidratos totais e proteínas. Devido à alta umidade do fruto foi observada uma pequena concentração de lipídios. A polpa do noni não representa uma boa fonte de fibras dietéticas, porém é rico em potássio, o que pode tornar o fruto fonte deste mineral. 


\title{
5 Agradecimentos
}

Os autores agradecem ao produtor Irineu Brondani pelo fornecimento das amostras, ao IFMT - Campus Cuiabá - Bela Vista por disponibilizar os laboratórios, materiais e reagentes para a execução das análises, ao Laboratório de Farmacognosia da UNIC pela triagem fitoquímica e ao Laboratório de Análises de Contaminantes Inorgânicos do Departamento de Química da UFMT pela determinação da concentração de Na e K nas amostras.

\begin{abstract}
This study aimed to characterize the physicochemical pulp without seeds and analyze preliminary qualitative phytochemical profile of the pulp and extracts of noni fruit, Morinda L. citrofolia produced in the Cuiabá city - MT. The fruits of Morinda citrifolia Linn were purchased from a producer of the urban perimeter. For phytochemical analysis were used raw fruits and for physicochemical determinations were purchased pulps chilled and packaged in polyethylene container sold in the city. Phytochemical analysis revealed the presence of different secondary metabolites suggesting the importance of other studies on these substances and their pharmacological roles and / or functional. Regarding the physicochemical parameters, the results indicated that the pulp without seeds has $90 \%$ water and dry matter consists mainly of total carbohydrates and proteins and that the amount of lipids is very small. It noted a high concentration of potassium, which suggests that this result can be considered a source of element, but should be used with caution by patients with kidney disease.
\end{abstract}

Key-words: Morinda citrifolia, physicochemical analysis, phytochemical analysis.

\section{Referências}

ASSOCIAÇÃO BRASILEIRA DE EMPRESAS DE VENDAS DIRETAS (ABEVD). Disponível em: <http://www.abevd.org.br> Acesso em: 14 de junho de 2012

BRASIL. MINISTÉRIO DA SAÚDE - AGÊNCIA NACIONAL DE VIGILÂNCIA SANITÁRIA. Portaria no 27, de 13 de janeiro de 1998 - Regulamento Técnico Referente à Informação Nutricional Complementar. Brasília, 1998. BARROS, S. P. N.; MAIA, G.A.; BRITO, E.S. SOUZA NETO, M. A.; SOUSA, J.A. Caracterização Físico-Química da polpa de noni (Morinda critriofolia L.). In: $54^{\text {th }}$ Annual Meeting of the Interamerican Society for Tropical Horticulture. Anais... Vitória: XX Congresso Brasileiro de Fruticultura, 2008.

CANUTO, G. A. B.; XAVIER, A. A. O.; NEVES, L. C.; BENASSI, M. T. Caracterização físico-química de polpas de frutos da Amazônia e sua correlação com a atividade anti-radical livre. Revista Brasileira de Fruticultura, v. 32 , p. 1196-1205, 2010. http://dx.doi.org/10.1590/S0100-29452010005000122

CARVALHO, R. M.; NASCIMENTO, L. C.; CHAVES, D. C.; RODRIGUES, W.M. Caracterização Físico-Química de Morinda citriofolia (noni) cultivado no município de Zé Doca, Maranhão, Brasil. In: $63^{\circ}$ Reunião Anual da Sociedade Brasileira de Progresso da Ciência. Resumos... Goiânia: SBPC, 2011. Disponível em: < http://www.sbpcnet.org.br/livro/63ra/trabalhosjoveml.htm> Acesso em 26 jun. 2012.

CECHI, H.M. Fundamentos teóricos e práticos em análise de alimentos. 2. ed. rev. Campinas: UNICAMP, 2003. $208 \mathrm{p}$.

CHITARRA, M. I. F.; CHITARRA, A B. Pós-colheita de frutos e hortaliças: Fisiologia e manuseio. Lavras: ESAL/FAEPE, 2005. 289p.

CHUNHIENG, T. Développement de nouveaux neutraceutiques à partir de graines et fruits d'origine tropicale: application a la noix du Brésil Bertholettia excelsa et au fruit de Cambodge Morinda citrifolia. 2003. 181 f. Thèse (Docteur) - Université de Nancy, France, 2003.

CORREIA, A. A.;GOnZAGA, M. L. C; AQUinO, A. C.; SOUZA, P. H. M.; FIGUEIREDO, R. W.; MAIA, G. A. Caracterização química e físico-química da polpa de noni (Morinda citrifolia) cultivado no Estado do Ceará. Revista Alimentos e Nutrição, v. 22, n. 4, p. 609-615, 2011.

COSTA, A. B. Atividade Antioxidante in vitro e Antifúngica do noni (Morinda citrifolia L.). Dissertação de mestrado. Universidade federal do Piauí - Programa de Pós Graduação em Alimentos e Nutrição. Teresina, 2001. 
DENG, S.; PALU, A. K.; WEST, B. J.; SU, C. X.; ZHOU, B. N.; JENSEN, J. C. Lipoxygenase inhibitory constituents of the fruits of noni (Morinda citrifolia) collected in Tahiti. Journal of Natural Products, v. 70, p. 859-862, 2007. http://dx.doi.org/10.1021/np0605539

EUROPEAN COMMISSION. Scientific Committee of Food, 2002. Opinion of the Scientific Committee on Food of Tahitian Nonis Juice. SCF/CS/ DOS/18 ADD 2. Belgium.

HEINICKE, R. M.. The pharmacologically active ingredient of Noni. Bulletin of the National Tropical Botanical Garden, 1985.

INSTITUTO ADOLFO LUTZ. Métodos Físico-Químicos de Análise de Alimentos. 4. ed. 1 ed. dig. São Paulo: IAL, 2005 .

KRAUSE; M. V.; MAHAN, M. S. Alimentos, Nutrição \& Dietoterapia. 7 ed. São Paulo: Roca, 1991.

KAMIYA, K. ; HAMABE, S. H.; MURAKAMI, R.; TOKUYAMA, S.; SATAKE, T. Chemical constituents of Morinda citrofolia roots exhibit hypoglycemic effects in streptozotocin-induced diabetic mice. Pharcaceutical Society of Japan, p. 935-938, 2008.

LIN, C. F.; NI, C. L.; HUANG, Y. L.; SHEU, S. J.; CHEN, C. C. Lignans and anthraquinones from the fruits of Morinda citrifolia. Natural Product Research, v. 21, p. $1199-1204, \quad 2007$. http://dx.doi.org/10.1080/14786410601132451

MANICA, I.; KIST, H.; MICHELETTO, E.L.; KRAUSE, C.A. Competição entre quatro cultivares e duas seleções de goiabeira. Pesquisa Agropecuária Brasileira, Brasília, v. 33, n. 8, p. 1305-1313, 1998.

MATOS, F. J. A. Introdução à fitoquímica experimental. 2 ed. Fortaleza: Edições UFC, 1997. 137 p.

MUlLER, J.C. Toxicidade Reprodutiva da Morinda citrifolia Linn. Dissertação de mestrado. Universidade Federal do Paraná - Curso de Pós Graduação em Farmacologia. Curitiba, 2007.

PALACIOS, M. Poder curativo e y nutricional del noni "La fruta milagrosa". 2ª ed. Lima: Ed. Miguel Ángel, 2004. $198 \mathrm{p}$.

SAMPAIO, C. G. Estudo químico bioguiado das sementes de Morinda citrifolia Linn (NONI) e suas aplicações. 2010. Fortaleza. 104 p. Dissertação (Mestrado em Química na área Química Orgânica) Centro de Ciências, Departamento de Química Orgânica da Universidade Federal do Ceará. Ceará.

SILVA, L. R.; MEDEIROS, P. V. Q.; LEITE G. A.; SILVA, K. J. P.; MENDONÇA, M.; SOUSA, J. L. Caracterização do fruto de noni (Morinda citrifolia L.). Horticultura Brasileira, v. 27, n. 02, p. S267-S271, 2009.

SHOVIC, A. C.; WHISTLER, W. A. Food sources of provitamin A and vitamin C in the American Pacific. Journal Tropical Science, v.41, p. 199-202, 2001.

WANG, M. Y.; WEST, B.; JENSEN, C. J.; NOWICKI, D.; SU, C., PALU, A. K. , ANDERSON, G. Morinda citrifolia (Noni): A literature review and recent advances in Noni research. Acta Pharmacologica Sinica. v. 23, n. 12, p. 1127$1141,2002$.

WEST, B. J.; DENG, S.; JENSEN, C. J. Nutrient andphytochemical analyses of processed noni puree. Food Research International, v. 44, p. 2295-2301, 2011. http://dx.doi.org/10.1016/j.foodres.2010.09.038

ZIN, Z. M.; ABDUL-HAMID, A.; OSMAN, A. Antioxidative activity of extracts from Mengkudu (Morinda citrifolia L.) root, fruit and leaf. Food Chemistry, p. 227-231, 2002. http://dx.doi.org/10.1016/S0308-8146(01)00402-2

Submetido em 15 fev. 2013, Aceito para publicação em 20 dez. 2013. 